\title{
MECANISMOS DESENVOLVIDOS POR IDOSOS PARA ENFRENTAR A HIPERTENSÃO ARTERIAL ${ }^{1}$
}

\author{
MECHANISMS DEVELOPED BY OLD-AGED PEOPLE TO FACE ARTERIAL \\ HYPERTENSION
}

\section{MECANISMOS DESARROLLADOS POR ANCIANOS PARA ENFRENTAR A LA HIPERTENSIÓN ARTERIAL}

Taciana Cavalcante de Oliveira* Thelma Leite de Araujo**

\begin{abstract}
Oliveira TC, Araujo TL. Mecanismos desenvolvidos por idosos para enfrentar a hipertensão arterial. Rev Esc
\end{abstract} Enferm USP 2002; 36(3): 276-81.

\section{RESUMO}

Objetivamos investigar estratégias de enfrentamento, elaboradas por idosos portadores de hipertensão arterial, participantes de um grupo de auto-ajuda, em acompanhamento terapêutico. Os mecanismos de enfrentamento corresponderam à fé em Deus, apoio da família, realização de atividades ocupacionais, lazer e participação grupal. Alguns idosos citaram a estrutura familiar como pilar de sustentação para um melhor seguimento da terapêutica, permitindo assim a elaboração de respostas adaptativas. Concluimos que, apesar de todas as perdas sentidas e referidas, os idosos buscam ativar mecanismos que propiciem respostas adaptativas à situação de saúde-doença.

PALAVRAS-CHAVE: Idoso. Hipertensão. Comportamento. Enfermagem.

\section{ABSTRACT}

We objectified to investigate facing strategies elaborated by old-aged people which were attacked by arterial hypertension, being participants of a self-helping group, in a therapeutic accompaniment. The facing mechanisms corresponded to faith in God, family support, occupational activities accomplishment, leisure activities and group participation. Some old-aged people mentioned the family structure as the sustentation pillar for a better therapeutic following, making the elaboration of adaptative answers possible. We concluded that, in spite of all the felt and referred losses, the old-aged people searched to active mechanisms that propitiate adaptative answers to the health-disease situation.

KEYWORDS: Senior. Hypertension. Behavior. Nursing.

\section{RESUMEN}

Tuvimos como objetivo investigar las estrategias de enfrentamiento desarrolladas por ancianos portadores de hipertensión arterial, participantes de un grupo de autoayuda, bajo seguimiento terapéutico. Los mecanismos de enfrentamiento correspondieron a la fe en Dios, al apoyo de la familia, a la realización de actividades ocupacionales, a la diversión y participación grupal. Algunos ancianos refirieron a la estructura familiar como el pilar de sustentación para un mejor seguimiento de la terapéutica, permitiendo asi la elaboración de respuestas adaptativas. Se concluyó que, además de todas las pérdidas sentidas y referidas, los ancianos buscan activar mecanismos que le propicien respuestas adapativas a la situación de salud-enfermedad.

PALABRAS-CLAVE: Anciano. Hipertensión. Comportamiento. Enfermería

1 Originalmente parte da dissertação OLIVEIRA, T. C. O conviver de idosos portadores de hipertensão arterial: avaliação do processo adaptativo. (Dissertação) Fortaleza (CE) - Departamento de Enfermagem, Universidade Federal do Ceará; Inserida no Projeto Integrado Auto-ajuda nas Alterações da Pressão Arterial- CNPq (520445/97-0). Contou com o apoio financeiro da CAPES."'

* Enfermeira. Mestre em Enfermagem. E-Mail: tacianna@yahoo.com

** Enfermeira. Doutora em Enfermagem. Professor do DENF/UFC. Coordenadora do Projeto Integrado Auto-ajuda nas Alterações da Pressão Arterial. E-Mail: thelma@ufc.br 


\section{INTRODUÇÃO}

A constante interação das pessoas com seu ambiente está evidenciada por mudanças internas e externas. Em um mundo, em processo de transformação permanente, as pessoas necessitam manter sua própria integridade, o que requer uma constante adaptação (2). Nesse contexto, está inserido o idoso, com necessidade de adaptar-se, continuamente, ao processo de envelhecimento que envolve a manutenção da sua integridade, nos aspectos biológicos, psicológicos, sociais e espirituais.

Diante do exposto, percebemos que o envelhecimento poderá ser um momento muito dificil para algumas pessoas, uma vez que envolve outras esferas, além da biológica, podendo gerar comportamentos dos mais variados, com características adaptativas ou não.

Observações trazidas por vários autores, (3-5) nos revelam que a população de idosos cresce a cada dia e, com ela, também a necessidade de uma assistência mais adequada, com ênfase em uma melhor qualidade de vida, na tentativa de contribuir para um envelhecimento mais promissor. Menos numerosos, porém, são os que se interessam pelo idoso, principalmente pelo portador de alguma doença e/ou que possui baixo poder aquisitivo, considerado, muitas vezes, um "fardo" para a sociedade e, até, para a família. Percebemos, com isso, que, para o idoso usufruir de uma vida longa, com mais qualidade, é preciso haver um investimento maior nas ações de caráter preventivo, evitando maleficios provenientes de várias doenças que podem acometê-lo durante o processo de envelhecimento.

Dada a progressiva perda funcional, órgãos e sistemas podem sofrer alterações que vão sendo somadas e transformadas em diversas doenças crônicas. Essa situação merece uma atenção especial, principalmente pela possibilidade de causar seqüelas das mais variadas, caso não haja um controle rigoroso.(4)

Considerando o relatado, destacamos as doenças cardiovasculares, como um fator de grande representatividade no aumento do risco de morbidade e mortalidade da população geriátrica. Dentre essas, merece destaque a HAS, por atingir, aproximadamente, $50 \%$ da clientela referida. Sendo assim, percebemos a necessidade de procedimentos específicos que possam contribuir para a melhoria da qualidade de vida do idoso, portador dessa doença.

Esclarecem Martins(6), que a hipertensão arterial sistêmica poderá levar a uma dramática alteração no estilo de vida das pessoas, principalmente pelas restrições impostas pelo tratamento, farmacológico ou não, exigindo uma forte cooperação por parte do cliente.
Em relação à doença, em si, podemos afirmar que o grande problema da hipertensão se baseia, principalmente, em seu caráter silencioso. Assim, na maioria dos casos, o cliente não aparenta ter nenhum sintoma, relutando, por isso, em tomar os medicamentos anti-hipertensivos, os quais, ocasionalmente, levam-no a sofrer efeitos colaterais(4) Esta concepção, como assinala o autor, poderá convergir para uma resistência à terapêutica farmacológica estabelecida, refletindo, possivelmente, em dificuldades de adaptação e respostas de caráter ineficaz. Cumpre ressaltar, ainda, que a mudança no estilo de vida, configurando a terapêutica nãofarmacológica, nem sempre tem uma boa aceitação. Diante dessa realidade, podemos perceber a importância da questão, principalmente se estiver inserida no contexto da população idosa, que, em razão do processo de envelhecimento, fica mais suscetivel a várias mudanças.

Cabe, portanto, aos enfermeiros, implementar ações específicas de cuidado à saúde do idoso, portador de hipertensão arterial, orientando-o para um novo conviver com a terapêutica indicada e possibilitando a compreensão de todo o contexto que a envolve.

Tendo em vista a necessidade de apoiar o cuidado de enfermagem em um referencial teórico, para a elaboração deste estudo adotamos a teoria de adaptação de Sister Callista Roy (7) Justificamos a escolha pela crença de que seus pressupostos favorecem uma melhor análise da situação vivenciada pelo idoso portador de hipertensão arterial. Acreditamos que a hipertensão, por ser definida como uma entidade multifatorial, poderá causar inúmeros estímulos e, conseqüentemente, respostas das mais variadas ao portador, especificamente se este for um idoso. Com isso, percebemos ser de extrema importância a aplicação do modelo teórico, já que, no decorrer do tratamento da doença, é imprescindivel a participação efetiva do cliente e a utilização de mecanismos de compensação aos estímulos que recebe. Nesse contexto, objetivamos investigar estratégias de enfrentamento, elaboradas por idosos portadores de hipertensão arterial, em acompanhamento terapêutico. Acreditamos que a partir do conhecimento das estratégias de enfrentamento adotadas pela referida população, poderemos estimular o idoso a reforçá-las para um melhor seguimento da terapêutica, minimizando assim comprometimentos posteriores, que poderão surgir se o processo de adesão por parte do cliente não for eficaz. 


\section{REFERENCIALTEÓRICO- METODOLÓGICO}

\section{Aspectos Gerais da Teoria de Adaptação}

A teórica menciona que a visão da pessoa, como um sistema adaptativo, possui quatro elementos: o input, que são os estímulos; os controles, que são os mecanismos de enfrentamento; o output, que são as respostas e o feedback ou retroalimentação. Input ou estímulos, são definidos como aqueles que provocam uma resposta e podem se originar do ambiente interno ou externo. Certos eventos podem constituir estímulos internos específicos, como o nível de adaptação (Roy $\&$ Andrews, 1999).

O modelo em estudo, descreve três classes de estímulos: focais, contextuais e residuais. Os estímulos internos ou externos, que confrontam imediatamente a pessoa, constituem os estimulos focais. Os estimulos contextuais, são todos os outros estímulos presentes na situação e que contribuem para o efeito do estímulo focal. E, por fim, os residuais, são estímulos presentes ou não na pessoa, relevantes à situação, mas cujos efeitos são indefinidos.

Os estímulos referidos anteriormente, ativam mecanismos de enfrentamento (controle), definidos como mecanismos inatos ou adquiridos, para responder às mudanças do ambiente. Os mecanismos de enfrentamento inatos, são geneticamente determinados, sendo geralmente vistos como processos automáticos, com respostas automáticas, inconscientes e inatas. Já os mecanismos de enfrentamento adquiridos são desenvolvidos mediante estratégias, como a aprendizagem, sendo a resposta deliberada, consciente e adquirida.

Tais mecanismos irão desencadear respostas (output), classificadas em adaptativas e ineficazes. As respostas denominadas de adaptativas são todas aquelas que promovem a integridade da pessoa, em termos de metas de sobrevivência, crescimento, reprodução e controle; respostas ineficazes, são as que interrompem ou não contribuem para essa integridade. Em consideração ao indivíduo, como um sistema adaptativo, o modelo de Roy categoriza os mecanismos de enfrentamento em inato e adquirido, dentro de dois subsistemas maiores: o regulador e o cognoscente. $\mathrm{O}$ Subsistema Regulador recebe estímulos provenientes do meio interno da pessoa, processando respostas, automaticamente, através dos sistemas químico, neuronal e endócrino. O Subsistema Cognoscente recebe estímulos, tanto do ambiente interno quanto do externo, respondendo aos mesmos através de quatro canais cognitivos- emocionais: perceptual! processamento de informações, representando a atividade de atenção seletiva, codificação e memória; a aprendizagem, envolvendo processos de imitação, reforço e "insight"; o julgamento, voltado para solucionar problemas e tomar decisões; e emoção, através da qual a pessoa busca alivio da ansiedade e afeto.

\section{Procedimentos Metodológicos}

O estudo foi desenvolvido com onze idosos participantes de um projeto de extensão, denominado "Grupo Vida", vinculado ao Centro de Desenvolvimento Familiar (CEDEFAM), uma unidade da Universidade Federal do Ceará, localizada em zona periférica de Fortaleza.

Para a composição da população foram estabelecidos os critérios de inclusão a seguir: ter 60 anos a mais; ser portador de hipertensão arterial e estar em tratamento institucional; estar consciente, orientado, com fala e audição preservados e aceitar participar voluntariamente do estudo. $\mathbf{O}$ único critério de exclusão adotado foi a coexistência de outras doenças crônicas.

A coleta de dados foi realizada junto ao cliente, em seu domicílio, no período de março a junho de 2000. Utilizamos um roteiro de entrevista, baseado no modelo de Roy ${ }^{(8)}$, com ênfase para os mecanismos de enfrentamento.

O roteiro de entrevista está dividido em três partes: a primeira, para registro de dados sóciodemográficos, tais como idade, sexo, cor, estado civil, escolaridade, renda familiar, religião, ocupação, procedência e tempo de tratamento; a segunda, contemplando perguntas inerentes aos mecanismos de enfrentamento elaborados pelos idosos frente ao diagnóstico e tratamento da hipertensão arterial; e a última, utilizada para as observações complementares, julgadas pertinentes.

Para analisar os dados, utilizamos as seis fases da análise estrutural de Rifiotis (9): 1. identificação das seqüências narrativas; 2. descrição dos elementos estruturais; 3. Colocação em seqüência das funções cardinais e em paralelo as de catálise; 4. identificação dos elementos do nível integrativo; 5. identificação dos investimentos semânticos; 6 . confrontação entre o quadro inicial e final.

Finda a etapa de organização dos depoimentos, partimos para o processo de análise, compreendendo, explicando e interpretando os discursos, à luz do referencial teórico escolhido, bem como utilizando literatura pertinente ao tema.

Além de contarmos com a autorização da coordenadora de enfermagem do CEDEFAM, o projeto foi submetido e aprovado pelo Comitê de Ética em Pesquisa do Complexo Hospitalar da Universidade Federal do Ceará, atendendo a Resolução 196/96, sobre pesquisas que envolvem seres humanos ${ }^{(10)}$. 
Após essa etapa, entramos em contato com a coordenadora do grupo de auto-ajuda, solicitando autorização para a realização da pesquisa. A partir daí, os sujeitos da pesquisa foram contactados para apresentação do projeto e esclarecimento acerca dos objetivos, sendo-lhes assegurado anonimato diante dos achados, bem como flexibilidade de se retirarem a qualquer momento da pesquisa. Os idosos tomaram conhecimento do termo de concordância e, só após a sua aceitação, iniciamos a coleta de dados.

Para a organização dos discursos os idosos receberam nomes fictícios, resguardando, assim, o sigilo de suas identidades.

\section{DESCRIÇÃO E ANÁLISE DOS ACHADOS}

\section{Caracterização dos Idosos}

Os idosos que participaram do estudo, residem em zona periférica de Fortaleza, nas adjacências do local do estudo. De forma geral, apresentaram baixos niveis sócio-econômico e escolar. O grupo estudado pertence à faixa etária de 60 a 84 anos, sendo composto por dez mulheres e um homem. Esses dados, relativos à idade, confirmam um risco aumentado para morbi-mortalidade cardiovascular, principalmente pelo fato dos idosos já serem portadores de hipertensão arterial. Sete referiram ter cursado as séries iniciais do primário (atual ensino fundamental) e quatro são analfabetos. Quatro dos idosos eram viúvos, quatro casados, dois separados e um solteiro. A viuvez foi relatada como algo negativo, causador de sentimentos de medo, ansiedade e solidão. A ausência do companheiro (a) favorece o estabelecimento de um sentimento de insegurança constante.

A aposentadoria, referida por sete idosos, também foi vista como algo causador de conflitos, principalmente pelo fato de não suprir, adequadamente, as reais necessidades, tais como: alimentação, saúde, moradia e lazer. Além disso, muitas vezes, a aposentadoria serve de suporte para complementar a renda familiar.

\section{Mecanismos de Enfrentamento}

Neste capitulo, procuramos descrever os principais mecanismos de enfrentamento utilizados pelos idosos para um viver compensador. Fazendo uma breve revisão, podemos mencionar que uma vez ativados pelos estímulos focais, contextuais e residuais, os mecanismos de enfrentamento irão desencadear respostas, que poderão ter um caráter adaptativo ou ineficaz enfrentamento das situações internas ou externas, é necessário para a manutenção da integridade do indivíduo. Sendo assim, seguiremos com os principais achados relativos aos mecanismos de enfrentamento elaborados pelos idosos.
A fé em Deus foi um dos mecanismos mais utilizados pelos idosos. Seguem-se, a respeito, algumas falas ilustrativas:

...Às vez, eu saio lá para debaixo dos pés de cajueiro, das mangueiras. Aí, lá eu choro, eu peço força a Deus...(Cléo) ...eu tenho que ter calma para poder ter um pouco de saúde... Mas ai eu peço força a Deus e me controlo...(Dara) ...tenho fé em Deus, confio que um dia eu vou ficar boa (Fernanda) ...eu vou orar a Deus, pedir que Deus faça em mim que se cumpra a vossa vontade e não a minha... (Helen).

No discurso de Cléo, percebemos que a idosa costuma buscar o apoio de Deus para enfrentar melhor os problemas da vida cotidiana, processando assim uma resposta através do subsistema cognoscente. Dara tem consciência que a calma (subsistema regulador) é imprescindivel para uma manutenção adequada do estado de saúde. Percebemos, com isso, que está tentando mudar o seu comportamento, partindo da premissa que o estresse e o nervosismo, se não controlados adequadamente, poderão influenciar, sobremaneira, os niveis da sua pressão arterial, interferindo, diretamente, na expectativa de vida. O autocontrole almejado, tem sido desenvolvido em função da grande fé que tem em Deus. A fé em Deus, por sua vez, tem funcionado como um subsistema cognoscente e mecanismo adaptativo, uma vez que possibilita a manutenção de sua integridade como pessoa. Fernanda e Helen, também fazem uso do subsistema regulador (fé em Deus) para um melhor processo de adaptação.

O processo de adaptação ocorre, não raro, de forma inconsciente, quando, por exemplo, o indivíduo entrega a Deus os seus sofrimentos. Não há uma ação deliberada de ajustamento mas, o fato de transferir o sofrimento inevitável a um ente superior, no nosso caso, Deus, é uma estratégia adaptativa para se livrar do fardo que, sozinho não seria capaz de carregar. Essa maneira de lidar com o estresse, advindo da realidade, da sensação ou sentimento de perda, estende-se a vários espaços, onde houver limitação ou incapacidade de realizar tarefas antes possiveis. Assim, o idoso transfere, ou melhor, divide com um ente mais forte, a sobrecarga que é viver em um mundo não adaptado às suas demandas específicas ${ }^{(10)}$

A família também foi citada como importante fonte de apoio:

Meus filhos me dão auxílio...(Beatriz) ...Eu procuro enfrentar as mudanças na minha vida após a pressão alta com apoio dos meus filhos, porque a minha vida são os meus filhos. Graças a Deus, eu adoro eles... (Jéssica). 
Araújo(11), ao realizarem estudos com doentes cardíacos, perceberam a forte influência do componente familiar, como estímulo ao enfrentamento de problemas oriundos desta condição.

Os discursos de Beatriz e Jéssica revelam a importância que é dada às relações de interdependência, como meio de permitir não só a troca de afeto, mas, também a construção de mecanismos compensatórios mais sólidos. Observa-se, pelos relatos, que a familia motivou nesses idosos, o emergir de respostas adaptativas.

Lopes (13) em estudo sobre o modelo teórico de Roy, revelam que o objetivo básico do modo de interdependência, é a promoção de uma resposta adaptativa, capaz de levar a uma adequação afetiva, tida como sensação de segurança que nutre o relacionamento com os outros. Para tal, faz-se necessária a presença de sistema de suporte.

Outro apoio referido foi a participação no grupo de auto-ajuda, que é sentido como um ambiente de distração, de movimentação, de alegria e de prazer:

... para o Grupo... para lá sempre eu vou, gosto... acho muito bom, há diversão para gente. Me sinto bem (Beatriz) ...Ave Maria, o grupo de lá (grupo de auto-ajuda), quando eu num tô assim viajando eu num falto não. Eu gosto, é muito bom, só aquela atenção que dão a gente, só aqueles exercícios também que faz com a gente, já é uma coisa que ajuda muito a gente. Eu gosto, já tô acostumada lá... eu acho é bom... (Fernanda).

A participação no grupo de auto-ajuda é referida como algo muito importante, não só por permitir um envelhecimento mais saudável, mas por promover, também, uma ocupação, desvinculando o idoso de uma possivel ociosidade. Ferraz, (14) referem que a ociosidade pode ser um determinante de sentimentos de não realização, da falta de perspectivas, de inutilidade, interferindo no autoconceito e na auto-estima. Ao investigar a qualidade de vida de um grupo de idosos, inseridos em uma instituição pública de recreação, os mesmos autores constataram que encontraram na instituição, alternativas de manutenção do convívio social e de envolvimento em atividades fisicas, recreativas e ocupacionais, levando-os a ter uma percepção de autorealização, felicidade e bem-estar, parâmetros mais significativos na avaliação da qualidade de vida.

Lopes (5), fazendo menção às mudanças constantes do mundo moderno e sua influência no estilo de vida das pessoas, acreditam que o trabalho em grupo, poderá contribuir para a melhoria da qualidade de vida. Além disso, possibilita o estabelecimento de ajuda como estratégia para a percepção, discussão e aprendizado de habilidades, que venham a contribuir para um redirecionamento e conseqüente mudanças de determinados hábitos e atitudes que influenciam a vida diária.

Outro aspecto importante para a manutenção de um melhor estilo de vida, citado por alguns idosos, foi a execução de atividades ocupacionais e recreativas, bem como o contato com outras pessoas, participantes do sistema de apoio. Vejamos:

...gosto muito de andar...de passear, mas nem todo o tempo dá... (Beatriz) ...gosto de jogar dominó... de conversar, dessas coisas assim que eu gosto... (Cléo) ...se eu estou em casa eu estou sempre fazendo um crochêzinho... fazendo qualquer coisa...para num ficar assim pensando. Eé bom para gente se movimentar, né? (Eucléia) ...num gosto de tá parada, eu num gosto de tá parada não... (Fernanda) ...As vez, eu faço alguma coisa... fiz até um crochê, fiz umas varandas para uma rede, viu?... (Helen).

Os discursos revelam práticas afirmativas de vida, com ênfase para atividades que permitam o movimento. Os idosos procuram utilizar os recursos existentes. Buscam, em verdade, uma qualidade de vida e para isso lançam mão de mecanismos de compensação que possibilitem o estabelecimento de respostas adaptativas.

Abnara teve um acidente vascular cerebral há aproximadamente dois anos, e apresenta uma certa restrição de movimentos em uma das mãos, utilizando o crochê como meio de prevenir uma atrofia muscular (finalidade terapêutica). Ao afirmar:...quando a mão tá assim mais ou menos, eu vou fazer crochê, porque eu num quero ficar sem fazer nada..., demónstra que além de estar movimentando as mãos, está realizando algo que lhe dá muito prazer e a sensação de que ainda é uma pessoa produtiva e capaz. Sente-se útil, por assim dizer. Percebemos, de maneira geral, que o subsistema regulador está possibilitando aos idosos respostas adaptativas.

Para enfrentar as mudanças, é também importante a capacidade de realizar atividades que facilitem lidar melhor com elas. Cada um pode escolher, por exemplo, entre andar diariamente, movimentar-se de alguma forma, e ficar apático, passivo, acomodado, sentado o dia inteiro em frente à televisão, o que não é nada saudável(16)

\section{CONSIDERAÇÕES FINAIS}

A partir dos achados, podemos revelar que o adoecer traz consigo uma série de estereótipos, principalmente se tiver um caráter crônico, ao exemplo da hipertensão arterial. Sendo assim, percebemos que a doença e o seu tratamento funcionou como um 
estímulo para que o idoso elaborasse mecanismos de enfrentamento, capazes de ajudá-lo a manter-se, constantemente, adaptado. A elaboração de respostas adaptativas, frente à terapêutica da hipertensão, é imprescindivel para a manutenção de um envelhecer bem sucedido.

Os idosos do presente estudo assumiram essa postura, buscando formas alternativas para enfrentar melhor o processo de envelhecimento e/ou terapêutico.

As respostas adaptativas dos idosos (mecanismos de enfrentamento) às situações adversas, provenientes do momento de vida atual, corresponderam à fé em Deus, apoio da familia, realização de atividades ocupacionais e de lazer. Apesar de todas as perdas sentidas e referidas, os idosos buscam uma melhora no estado de saúde, e, desse modo, procuram se manter fisica e mentalmente ocupados. Com isso, observamos que, mesmo com certas limitações, tentam desenvolver práticas afirmativas de vida, em busca de uma longevidade, com mais qualidade de vida. E importante ressaltar que os idosos demonstram comportamentos positivos, não sendo referidas respostas ineficazes.

A estrutura familiar foi citada com um das mais importantes fontes de apoio. Percebemos, com isso, a relevância das relações familiares na vida do idoso, permitindo troca de amor, afeto, respeito e valor, indispensáveis para um envelhecer saudável e compensador. Além do mais, a relação com pessoas significantes, poderá contribuir, também, para que o idoso consiga se adaptar melhor à instabilidade do estado de saúde, relativa à presença da hipertensão arterial e de seu tratamento. Caso contrário, poderá se sentir desprotegido, inseguro e angustiado, com reflexo direto no processo de manutenção da saúde e qualidade de vida.

Os achados do nosso estudo, deverão retornar ao grupo abordado, modificando as estratégias utilizadas para o cuidado, procurando-se selecionar ações de enfermagem que favoreçam a adaptação dos idosos ao diagnóstico e ao tratamento da hipertensão arterial. O fortalecimento das fontes de apoio mencionadas, inclusive pelos próprios idosos, deve ser bastante estimulada. Isto significa valorizar as expressões e práticas de religiosidade e de vivência em grupo, mas, acima de tudo, a compreensão da importância da família no processo adaptativo dos idosos. A família deve ser incluída, obrigatoriamente, no planejamento do cuidado e nas intervenções, dada a importância evidenciada, e já comentada, nos discursos de seu papel, tanto no processo adaptativo, como nos modos de enfrentamento.

Acreditamos que a realização deste estudo, contribuiu de forma significativa para um olhar mais reflexivo a respeito da nossa prática profissional, enriquecendo-a e tornando possivel o desvelar de realidades, antes pouco conhecidas. Estudos posteriores, que avaliem melhor como a família pode realmente trabalhar em conjunto com a enfermagem, devem ser realizados para melhor sistematização das ações.

\section{REFERÊNCIAS BIBLIOGRÁFICAS}

(1)Oliveira TC. 0 conviver de idosos portadores de hipertensão arterial: avaliação do processo adaptativo. (Dissertação) Fortaleza (CE)- Departamento de Enfer-magem, Universidade Federal do Ceará; 2001.

(2)Galbreath JG. In: George JB. Teorias de enfermagem: os fundamentos à prática profissional. Porto Alegre: Artes Médicas, 2000. cap. 15, p.203-224.

(3)Assis M. O envelhecimento e suas conseqüências. In: Caldas C P. A saúde do idoso: a arte de cuidar. Rio de janeiro: UERJ, 1998. unid. 2, cap. 2, p. 39-48.

(4)Leme LEG. O envelhecimento. São Paulo: Contexto;1998.

(5)Veras RP. Aspectos demográficos. In: Caldas CP A saúde do idoso: a arte de cuidar. Rio de Janeiro: UERJ, 1998. unid.2, cap.3, p. 49-50.

(6) Martins LM, Franca AP, Kimura M. Qualidade de vida de pessoas com doença crônica. Rev Latinoam Enferm, Ribeirão Preto, 4(3): 5-18.

(7)Roy SC, Andrews HA. The Roy adaptation model. $2 \mathrm{n}^{\mathrm{d}}$ ed. Stamford: Appleton \& Lange, 1999.

(8)Christensen PJ. Assessment data collection of the individual client. In: Christensen PJ, Kennedy JW. Nursing process: application of conceptual models. 4 th ed. St. Louis: Mosby, 1995. p.70-77.

(9)Rifiotis T. Aldeias de jovens: a passagem do mundo do parentesco ao universo da politica em sociedade bantofalantes. Estudo da dinâmica dos grupos etários através da literatura oral, (Tese) São Paulo (SP): Faculdade de Filosofia, Letras e Ciências Humanas Universidade de São Paulo. 1994

(10)Ministério da Saúde. Conselho Nacional de Saúde. Resolução $n^{9}$ 196/96. Decreto $n^{\circ} 93.933$ de janeiro de 1987. Estabelece Critérios sobre Pesquisa Envolvendo Seres Humanos. Bioética, 4(2): 15-25.

(11)Silva MJ, Varela ZM. O conceito de adaptação na terceira idade: uma aproximação teórica. Arq Geriatr Gerontol, 1999; 3(1):25-29

(12)Araújo TL, Lopes MVO. A importância da família no comportamento do modo autoconceito. In: Alves MDS, Pagliuca LMF, Barroso MGT. Cultura e poder nas práticas de saúde: sociedade, grupo, família. Fortaleza: PósGraduação/DENF/UFC, 1999. pt.3, cap. 5, p. 145-153.

(13)Lopes MVO, Varela ZMV, Araujo TL. Marco conceitual para estudo da disfunção da reação de pesar em mulheres com infarto agudo do miocárdio. In: Damasceno MMC, Araujo TL, Fernandes AFC. Transtornos vitais do século XX: diabetes mellitus, distúrbios cardiovasculares, câncer, AIDS, tuberculose e hanseníase. Fortaleza: Fundação Cearense de Pesquisa e Cultura, 1999a. pt. 2, cap. 6, p. 47-54.

(14)Ferraz AF, Peixoto MRB. Qualidade de vida na velhice: estudo de uma instituição pública de recreação para idosos. Rev. Esc. Enferm USP 1997; 31(2): 316-338

(15)Lopes MVO, Araujo TL, Rodrigues DP Mulheres: ajuda para a qualidade de vida. In: Alves MDS, Pagliuca LMF, Barroso MGT. Cultura e poder nas práticas de saúde: sociedade, grupo, familia. Fortaleza: Pós-Graduação/DENF/UFC, 1999b. pt. 2, cap. 4, p. 87-96.

(16)Pereira ILL, Vieira CM. A terceira idade: guia para viver com saúde e sabedoria. Rio de Janeiro: Nova Fronteira, 1996.

Artigo recebido em 17/07/01

Artigo aprovado em 02/10/02 